duties, and is in better health than she has been for a number of years.

The chief point of interest in this case appears to be the total subsidence of the sarcinal vomiting succeeding immediately on the removal of the two large gall-stones from the stomach, and on her assuming a strictly fluid diet.

Gillingham, Dorset, Jan. 1861.

\section{9. athlitror}

OF THE PRACTICE OF

\section{MEDICINE AND SURGERY IN THE}

\author{
HOSPITALS OF LONDON.
}

Nulla est alia pro certo noscendi via, nisi quam plurimas et morborum et dissectionum historias, tam aliortum proprias, collectas habere et inter se comparare.-MongagN. De Sed. et Caus. ALorb., lib. 14. Procinium.

\section{CHARING-CROSS HOSPITAL.}

CONCURRENCE OE PURPURA WITH VALVULAR DISEASE OF THE HEART; THREE CASES ; RECOVERY.

(Under the care of Dr. HYde SALTER.)

THE following cases illustrate a concurrence which Dr. Salter states he has on several occasions remarked--that of purpura with valvular disease of the heart, though he believes that the connexion between the two is not direct, but mediate, throngh the intervention of a third condition, of which both the endocardial disease and the purpura are the results.

CASE 1. -Eliza $\mathrm{C}-$, a girl aged fifteen, but having a look rather of twelve or thirteen, thin, puny, and pale, though with evidently naturally a florid complexion, and having a good deal of the rheumatic aspect, was admitted with a loud, rough, mitral-systolic bruit, tumultuous heart's action, and shortness of breath on exertion. Her history was that she had had rheumatic fever two years before, which had affected the heart, and that since that time she had never been thoroughly well; her growth had been stopped; she was frequently liable to rheumatic pains, and suffered from palpitation on excrtion, and even without. It was in consequence of a gradual increase of these symptoms that she applied for relief. Under a treat. ment combining alkali, iodide of iron, and cod-liver oil, she gradually improved, and was discharged. She had left the hospital only a week or two, when she returned with both her legs covered with purpura-a profuse and thick rash-from the knees to the ankles. She seemed to have gone back in all respects since she left the hospital, partly, probably, from discontinuing the medicine and partly from not living so well. It was then learned that she had had an exactly similar attack some months before, and had since been liable occasionally to a few spots, but always in the neighbourhood of the shins. Under the use of quinine, sulphuric acid, good diet, and rest in the horizontal position, the purpura gradually died away, and in ten days or a fortnight was gone.

CASE 2.—William W-, a pale, anæmic-looking boy, aged fourteen, his aspect indicating a dash of struma in his constitution, was admitted June 23rd, 1860, with rheumatism, com. plicated with heart-disease. He states that he has always been a very healthy boy until last winter, when he caught cold, which brought on rheumatism, which however did not confine him to bed, and from which he soon recovered. Six weeks before his admission, the rheumatism came on again, principally affecting his hands, knees, and ankles; and for four weeks before his admission he found that on first getting into bed he was unable to lie down from palpitation, shortness of breath, and cough. On examining his heart, a mitral-systolic bruit was found, accompanied with tumultuous action of the organ. No dropsy. He was ordered a drachm of citrate of potass, in an ounce of decoction of cinchona, thrice a day; and half a drachm of syrup of the iodide of iron, in two drachms of codliver oil, also thrice a day. Five days after his admission spots of purpura hæmorrhagica appeared on the anterior aspect of his legs, most abundant on the front and inside of the shin; at first a thin sprinkling, but soon a thick rash. Under a treatment of sulphuric acid, quinine, and iron, the purpura gradually disappeared, but it was a fortnight before it was gone.

CASE 3.-J. N-, aged thirty-two, was admitted into Charing-cross Hospital, under Dr. Salter, on the 25th Septem. ber, suffering from general dropsy and purpura of both legs. The spots varied in size from that of a pin's head to that of a split pea, and were confined to the front of the leg from the knee to the ankle. On listening to the heart, a loud mitralsystolic bruit was heard; the heart's action in other respects was normal. There was no history of rhenmatism. The man had for years drunk too much, being employed in a brewery; his aspect was sallow; and the dropsy was supposed to depend upon renal disease, which further examination verified, as the urine was found to contain a good deal of blood and granular casts of the uriniferous tubes. The legs were ordered to be bandaged, the horizontal position to be maintained (indeed, the patient was confined to bed), and tonics and astringents were administered. Under this treatment the purpura and the œdema vanished together, and in ten days both were gone. But on the man leaving his bed subsequently, the purpura again appeared to a slight extent, and again disappeared on keeping the legs up and bandaging them.

With regard to the relation between the heart-disease and the purpura in these three cases, it could not be, as Dr. Salter remarked, direct, in any one of them. No doubt a certain form of purpura may be, and often is, directly caused by heart. disease; as in those cases where the general stasis of the circulation, brought about by the actual or virtual obstruction at the heart, produces so great a tension of the venules and capil. laries, that after relieving themselves to a certain extent by transudation they finally rupture, and blood escapes. The purpura in these cases always affects an enormously swollen limb, occurs only at the wind up of fatal cases, and is always preceded by the extremest symptoms of blood-stoppage. Now in these three cases nothing of the kind existed: in the first two there was no dropsy whatever; and in the third the dropsy amounted only to a slight general puffiness, with an absence of any mechanical blood stasis. In ueither of these cases did the mitral regurgitation perceptibly affect the systemic circulation.

To what then was the purpura due? In the first two cases to that special blood-poverty, that spanæmia, consequent upon and associated with the rheumatic condition, or rather to the fricbility and want of tone of the capillary wall consequent upon that blood-poverty. That this was so Dr. Salter felt the more sure because he had frequently observed and called atten. tion to the association of the rheumatic and hæmorrhagic ten. dency in cases where no heart-disease existed, and had also observed that one and the same set of peculiarities of physique was common to both these tendencies. In the third case Dr. Salter believed the hæmorrhage was due to that blood-debasement that is always produced by chronic anæmia, from which the patient was suffering, and of which his anæmic condition was indicative; but he was not prepared to say that the impediment in the cutaneous capillaries, which is probably the immediate cause of kidney dropsy, had nothing to do with the vessels of the cutis giving way.

The occurrence of the purpura, in all three cases, in the lower part of the lower extremities, and the assistance which the recumbent posture evidently gave to the cure, point out how much gravitation had to do in determining the seat of the hæmorrhage. No doubt this is the reason why the shin is so much more commonly the seat of purpura than any other part of the body. Dr. Salter considered that the bandaging of the legs, in the third case, was of decided advantage.

\section{LONDON HOSPITAL.}

PURPURA NAUTICA IN A SAILOR, ASSOCIATED WITH MEMIPLEGIA ; RECOVERY.

(Under the care of Dr. LitTLE.)

As some anthors consider purpura and scorbutus to be iden. tical, although the general symptoms of each are distinct, we include the two following cases in our series, as illustrating phenomena common to both-namely, cutaneous hæmorrhage. In the first case, the patient was a sailor, and had suffered from the privations at sea which give rise to scurvy. He was admitted with well-marked hemiplegia, which, considering his age, is a somewhat unusual complication. He, however, made a good recovery. 
In certain cases, congestions and effusions are known to take place in the lungs, pleura, pericardium, and cranium; when in the last, they give rise to drowsiness, coma, and apoplexy. It is very probable that the herifplegia in the present instance was due to something of this kind of a temporary nature, for the recovery would seem to show that the whole or the greater part of the effusion (whether sanguineous or otherwise) must have been absorbed.

We avail ourselves of the notes of Mr. D. H. Dyte, clinical clerk.

John $\mathrm{N} \longrightarrow$, aged twenty-one, a Swedish sailor, of sallow complexion, thin, and much emaciated, was admitted on the 21st June. He had just returned from a voyage to China, and there was a very liunited supply of provisions on board. On admission, which was three weeks after the commencement of his illness, he was suffering from extreme prostration, and was unable to walk or stand. He complained of great pain in his legs and thighs, which troubled him most at night. The gums seemed to form a double row, were spongy, and bled readily; breath very fetid. There were sugillated marks on the legs and thighs, and petechial spots on the integument generally. The skin felt thickened in some places, as if infiltrated with solid effusion; the legs in particular felt hard as a board. Bowels were neither constipated nor relaxed. (The patient stated that several of the crew were similarly affected.) His pulse was small and feeble. The right arm and leg were para. lysed, and entirely bereft of motion; face drawn to the opposite side, and the tongue when put ont was slightly protruded to the affected side. He at times spoke more intelligibly than at others. To have milk and beef-tea, four ounces of wine, and six ounces of lemon juice daily.

June 22nd. - Feels a little better; not so weak as yesterday. Allowed a chop in addition.

26th. - Feels much better; but the paralysis still continuing, a blister was ordered to the nape of the neck. To have half a pint of porter.

29th.-Improving; bowels rather confined. Calomel and jalap, one scruple, immediately.

July 3rd. - The discolorations of the skin are disappearing. $\mathrm{He}$ is able to move his leg; feels altogether better.

6 th. -Can raise his arm and stand a little.

10th. - Is able to walk about the ward; is much stronger and better. Extras discontinued. To have full diet, with green vegetables. His recovery was progressive, and on the 20 th he was discharged cured.

\section{ST. MARY'S HOSPITAL.}

SUDDEN FRACTURE OF THE LEG, THE RESULT OF FORMER SCORBUTIC DISEASE; RECOVERY WITII UNION OF THE BROKEN BONES.

(Under the care of Mr. URE.)

DURING the prevalence of scurvy, the bones are known to become softened, and fractures readily occur; indeed, it is stated that united fractures become re-opened, and in the young the epiphyses sometimes separate from each other. Although the bones remain brittle for a long time after an attack of scurvy, it is seldom that they break so readily, and with comparatively so little exertion, as in the following case. It seemed to be an unfavourable one for firm osseous union, yet that event occurred; but it was much assisted by the treatment pursued during the patient's stay in the hospital, which consisted of liberal diet, conjoined with tonic treatment.

In a former "Mirror," we placed upon record an instance of broken limb in a sailor affected with scurvy, under the care of Mr. Adams, at the London Hospital, in which the fracture did not show any disposition to unite until the patient was put under the effects of lemon-juice. (THE LANCET, vol. i. 1855, p. 393.)

R. W - a a thirty-five, admitted on the night of the 26 th of October, 1860 . While walking with his nsual gait along the pavement, about twenty minutes past six o'clock in the evening, he suddenly felt the bone of the right les suap across, as it were, in front of the limb; and on drawing up the leg he felt a bone snap behind. He found himself incayable of resting on the limb, and was conveyed in a cab to the hospital. It was ascertained that the tibia had sustained a nearly transverse fracture about two inches above the instep, and the fibula a similar fracture about an inch higher up. The leg was at once put up $n$ splints in the usual manner.
This man had been a sailor for seventeen years. He had scurvy in the gums three years ago, while at sea, from being restricted to a diet of salted provisions. He had been in this hospital on a previons occasion with an celematous affection of the opposite leg, which he attributed to a scorbutic cause. He suffered from rheumatic pains, and took with benefit compound tincture of guaiacum, and subsequently tincture of iron in infusion of quassia, also with benefit. His diet was of the most liberal kinl, and in the course of a few weeks solid union of the fractured bone had taken place, permitting of his discharge from the hospital early in December, in good health.

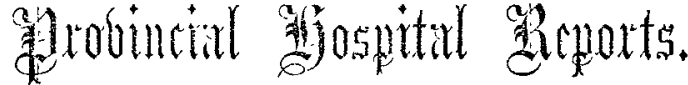

\section{NEWAKK HOSPITAL.}

TETANUS TREATED BY OPIUM.

\section{(Communicated by S. Jos, Esq.)}

Jour $\mathrm{P} \longrightarrow$, aged fourteen, a healthy-looking lad, gives the following account of his case:- On the 14th of October, while perspiring profusely, was obliged to work in a dranght. Felt chilled at the time, and in the evening was seized with rigors, pains in the joints, and vomiting. During the night, he began to experience some stiffness about the back part of his neck and lower jaw, rendering motion in these parts difficult and painful; this stiffness gradually extended down the back, and was speedily followed by an irresistible tendency on the part of the spine to arch backwards, with an occasional spasm, especially in the muscles at the lower part of the back. $\mathrm{He}$ does not remember having suffered from any injury or wound for some time past; but his mother states that about a month ago he trod npon a rusty nail; the wound festered, and remained open for about a week : she cannot say on which foot it was. On making an examination, no trace of anything like a scar remains.

On the I6th of Ostroer he was admitted into the Newark Hospital. The symptoms were as follows:-Decubitus on the shoulders and buttocks, the spine forming a complete arch; extremities rigidly extended; jaws fixed, leaving a fissure between the teeth sufficiently wide to admit the finger; pupils contracted and fixed; abdominal muscles remarkably hard; bowels constipated; has passed no urine for twenty-four hours; pulse 130 , small, and irritable; is literally soaked in perspiration, a dense steam arising from his body on removal of the bed-clothes; a somewhat violent spasm in the muscles of the back comes on about every half minute.

The last case of tetanus treated in this hospital having recovered under the use of opium, it was resolved to give it a fair trial in this instance. An injection with turpentine and gruel having been administered, he was ordered a grain of hard opium, with an ounce of the following mixture, every two hours: two drachms of tincture of colchicum, one drachm of carbonate of ammonia, two drachms of chloric ether, to one ounce of water. To have a glass of port wine every two hours, and beef-tea ad libitum; one drachm of tincture of opium at bed-time, and repeated during the night if restless. The body to be sponged with vinegar, and a belladonna plaster applied along the spine.

Oct. 17th.-Took both draughts; has had two hours' sleep; twitchings in the muscles of the back not so frequent; opisthotonos more complete, but there is not quite so much rigidity in the extremities; it is increased in the lower jaw, which is more closely set than yesterday. His pulse has increased in frequency, being 180, small and thready; perspiration less; takes wine and beef-tea in large quantities. To continue his pills and mixture, and take one drachm of the sedative solution of opium at bed-time, and repeat it if necessary; to have, also, one ounce of castor oil early in the morning.

18th. - Has had some hours' sleep. Spasms not ss frequent; fice not so much distorted; looks generally better; pulse 120 of moderate force and volume; rigidity of jaws and spine about the same. The oil acted well. He takes his nourishment and enjoys it. To continue the remedies, with the solution of opium at bed-time as usual.

19th. - Has passed a good night; says he feels better; pulse still 120 ; not so much rigidity in the upper extremities; the lower, the spine, and the jaw about the same. To continue the remedies. 